\section{(6) OPEN ACCESS}

PAPER

\title{
The social value of candidate HIV cures: actualism versus possibilism
}

\author{
Regina Brown, ${ }^{1}$ Nicholas Greig Evans ${ }^{2}$
}

\begin{abstract}
${ }^{1}$ Department of Global Health and Population, Harvard School of Public Health, Boston, Massachusetts, USA ${ }^{2}$ Department of Medical Ethics and Health Policy, University of Pennsylvania, Philadelphia, Pennsylvania, USA
\end{abstract}

\section{Correspondence to} Dr Nicholas Greig Evans, Department of Medical Ethics and Health Policy, University of Pennsylvania, 423 Guardian Drive, Floor 14, Philadelphia, PA 19104, USA Department of Philosophy University of Massachusetts, Lowell, 883 Broadway Ave, Lowell, MA 01854 nicholas_evans@uml.edu

Received 30 January 2016 Revised 20 May 2016 Accepted 15 June 2016 Published Online First 8 July 2016

\section{CrossMark}

To cite: Brown $\mathrm{R}$, Evans NG. J Med Ethics 2017:43:118-123.

\section{ABSTRACT}

A sterilising or functional cure for HIV is a serious scientific challenge but presents a viable pathway to the eradication of HIV. Such an event would be extremely valuable in terms of relieving the burden of a terrible disease; however, a coordinated commitment to implement healthcare interventions, particularly in regions that bear the brunt of the HIV epidemic, is lacking. In this paper, we examine two strategies for evaluating candidate HIV cures, based on our beliefs about the likelihood of global implementation. We reject possibilist interpretations of social value that do not account for the likelihood that a plan to cure HIV will be followed through. We argue, instead, for an actualist ranking of options for action, which accounts for the likelihood that a cure will be low cost, scalable and easy to administer worldwide.

\section{INTRODUCTION}

The control and eventual eradication of HIV, the viral cause of AIDS, would be a global victory, on par with the eradication of smallpox and the success of the polio vaccine. The prospect of a sterilising or functional cure for HIV is a serious scientific challenge but presents a viable pathway to the eradication of HIV. A cure that promises a HIV/ AIDS-free world would be so valuable that its pursuit could potentially justify unfavourable riskbenefit ratios for those participants, who understand and willingly accept the risks. ${ }^{1}$

Clinical research is typically justified to the degree that it delivers a socially valuable outcome. ${ }^{23}$ Yet, many drugs, vaccines and medical devices fail to reach the poor in low/middle-income countries because of high price, poor national and global healthcare infrastructure and public reluctance to adopt new health technologies. ${ }^{4}$ Given this, we ought to provide an account of the relationship between the potential for social value and the conditions under which that value can be realised. One position is that we ought to pursue research that results in clinically effective, widely available interventions: part of the appeal of HIV cure is the prospect of eradicating the disease.

One might argue that we should value research to the degree that we believe it will actually result in the eradication of HIV. Given what we know about social and political dimensions of medicine and public health in the developing world, we might select research based on our beliefs that it will result in a cure that is easily implemented in the developing world-one that is low cost, scalable and easy to administer-and eschew other lines of research that result in cures that are more expensive, harder to administer and present greater risk to human lives-that is, are less likely to realise their value.

On the other hand, it might be considered fatalist to pursue research only if it is feasible to implement given the current, less-than-perfect state of the world. Penicillin, which was initially so difficult to create that it was easier to extract the drug unmetabolised from a patient's urine than it was to cultivate more, ${ }^{5}$ is widely available today. From this perspective, it is not that questions of implementation are unimportant, but they are not relevant when assessing the social value of scientific research. Research that will possibly bring about a cure for HIV is, notwithstanding a lack of political will to implement that cure, socially valuable to pursue.

Here, we reject the latter view-what we call a 'possibilist' conception of social value-that a HIV cure is socially valuable to the degree that it provides a possible cure or provides knowledge for further research towards a possible cure. We argue, instead, in favour of the view that the social value of HIV cure research should be cashed out in terms of the actual likelihood that a HIV cure will eventuate and be implemented worldwide, potentially leading to the eradication of the virus. We call this view an 'actualist' conception of social value and defend this view against objections, before linking actualism to global health obligations in advance of a cure for HIV.

\section{THE VALUE OF A CURE}

The following promising cure options are currently planned or under early investigation:

A. Cell-based therapy. This approach involves genetic modification of $\mathrm{T}$ cells or stem cells collected by apheresis procedures in HIV-infected individuals. $^{6-9}$

B. Latency reversing agents. This approach targets latently infected cells using drug combinations that will 'shock' or reawaken and then 'kill' the virus. ${ }^{10-13}$ Some drugs currently being tested for reawakening latent virus have been approved for use in cancer treatment. ${ }^{6}$

C. Immune-based interventions. This cure strategy focuses on improving anti-HIV immune responses-approaches being considered include therapeutic vaccines and antibodies. ${ }^{14}$

D. Early intensive antiretroviral therapy (ART) treatment for neonates. This cure intervention is being explored as a means of attaining longterm ART-free remission of HIV transmitted at birth. ${ }^{15}$ 
All of this research is arguably valuable for its own sake, but its primary value inheres-like most medical research-in its instrumental relationship to human well-being. ${ }^{16}{ }^{17}$ Yet, well-being qua cures for disease occurs only if it can be translated to benefit the population that incurs the burden of that disease. Scientific knowledge that is worthwhile, all other things being equal, still needs to be ranked against other options that might be less technically sophisticated but more efficacious to implement.

This is particularly true in a scientific landscape in which nations invest significant funds into research in aid of important health priorities. In 2014, global investment in HIV/AIDS reached US\$20.2 billion; ${ }^{18}$ the US NIH spent approximately US\$3.0 billion on HIV/AIDS research, ${ }^{19}$ including US $\$ 114.4$ million on HIV cure research. ${ }^{20}$ Given the limited financial resources, increasing scientific evidence of the effectiveness of preventing HIV infection through pre-exposure prophylaxis using $\mathrm{ART}^{21-23}$ and the personal and societal benefits of early treatment with $\mathrm{ART}^{24}$ the allocation of substantial research dollars to HIV cure research over other chronic diseases requires justification.

Prioritising funding for future HIV cure interventions on the basis of social value is not straightforward. For instance, costly, high risk and medically complex procedures such as stem cell therapies might be a lower priority than immune-based therapies, if we rank the social value of candidate cures based on their ability to be implemented globally. However, this system for prioritising research could be considered myopic, holding potentially valuable research hostage to other political quagmires such as the fight for accessible global healthcare.

This tension mirrors the debate in normative ethics between actualism and possibilism. Frank Jackson and Robert Pargetter use the example of Professor Procrastinate receiving an invitation to review a book:

He is the best person to do the review, has the time, and so on. The best thing that can happen is that he says yes, and then writes the review when the book arrives. However, suppose it is further the case that were Procrastinate to say yes, he would not in fact get around to writing the review. Not because of incapacity or outside interference or anything like that, but because he would keep on putting the task off. (This has been known to happen.) Thus, although the best that can happen is for Procrastinate to say yes and then write, and he can do exactly this, what would in fact happen were he to say yes is that he would not write the review. Moreover, we may suppose, this latter is the worst that can happen. It would lead to the book not being reviewed at all, or at least to a review being seriously delayed. $^{25}$

Jackson and Pargetter argue that an actualist will agree that, given that Procrastinate will not actually review the book, he ought to decline (and thus avoid the worst from happening). A possibilist, however, would not consider the fact 'Procrastinate won't in fact do the review' to be relevant to ranking their state of affairs. If Procrastinate agrees to the review, it is _possible_ that the best outcome will be obtained (i.e. it the review is completed); that is what matters on a possibilist account.

Consider, now, a similar example:

Do-Good Nation believes that a particular compound could be used as a cure to a disease that infects millions of vulnerable people around the world. It is the best nation to pursue this cure -has the most qualified people, the resources, and so on. Let us assume that the best thing that can happen is that Do-Good successfully generates a novel compound that is used to cure the world of this infectious disease. ${ }^{\mathrm{i}}$ However, suppose that Do-Good knows that the drug will not be used; not because of physical limitations or logistical incapacity, but because no one will ensure the drug is implemented in a safe, simple, and scalable way. (This has been known to happen.) Thus, although the best thing that can happen is for Do-Good to develop the drug and cure millions, and exactly this could happen, what would happen were research pursued is that the drug would not be used. Moreover, we may suppose, this latter is the worst that can happen. It would lead to no cure, a wasted monetary investment that could be used for more realizable goals, and a loss of life through the disease.

The actor in question, rather than an individual, is a government or funding body that does have the means to implement a cure (or at least ensure the cure is safe, simple and scalable). In making decisions about funding research, then, the problem mirrors that of Procrastinate-the best thing is that the funder picks a candidate cure (or set of cures) and carries it (or them) through to completion. For an actualist, whether they actually will do this second part is a consideration relevant to which projects they choose to pursue.

There is another sense in which the tension between actualism and possibilism holds. Scientific research is typically a joint action in which mutually responsive agents, even if geographically disparate and belonging to separate institutions, work towards a common goal that is (only) achievable through group effort. ${ }^{26}$ In cases of joint action, a question arises about the degree of confidence an individual has that other members of group (loosely defined) will hold up their end of a joint action to accomplish some goal. ${ }^{27} 28$ The actualist-possibilist debate addresses the degree to which other agents will carry out their end of a joint action. For an actualist, knowing that a joint action will be unsuccessful because others would not carry their share of the load, especially if an individual can do good elsewhere, is a relevant consideration in whether or not that individual ought to pursue a particular goal.

To restate, when considering what type of HIV cure research to prioritise, given that value inheres in impact on human health, a possibilist will consider a candidate cure valuable to pursue if it is possible to implement. An actualist, conversely, will consider only those candidate cures that will be implemented-in the case of a sterilising or functional cure for HIV, those that are safe, simple and scalable - to be worth pursuing, but not those that are not actually going to be carried through to a cure.

\section{A LIMITED DEFENCE OF ACTUALISM}

A comprehensive defence of actualism is beyond the scope of this work. Rather, we offer a set of reasons to provisionally accept actualism in this context.

\section{The case for actualism}

First, actualism links claims about the value of scientific knowledge to actors and institutions that are in a position to promote

${ }^{\mathrm{i}}$ Note that while we use a global cure as our desirable state here, a similar example could be developed that assumes that our obligations qua developing cures for disease are only national, or at least prioritise citizens within a country ahead of others. Concerns about ranking our options for action still apply and what follows is still significant to discussions about primarily domestic obligations. (One might also look at claims that focus only on private researchers; here actualism still plays a role, although in more prescribed claims based on an actor's obligations _qua_private researcher.) We thank Danielle Bromwich for raising this point in a prior draft of this paper. 
those values. ${ }^{26}$ That is, the value of scientific research, in this case, is instrumental and contingent on the kind of world into which science and technology emerges. Actualists can be optimistic about science's potential, while being realistic about the value science has qua implementable cure.

Further, actualism bears-as per Jackson's and Pargetter's initial case-on ranking our options for action when setting research priorities. In our example, Do-Good only has two choices: pursue research or not pursue research. What is more likely, however, is that Do-Good has a larger set of options available: it could fund different kinds of research; design scalability or implementation research into a project's specific aims or promote other projects to pursue institutional reform, aid work or activism.

Actualism, finally, frames the value of scientific discovery in terms of its place in a social and political process of improving community health and makes room for ranking research aimed at a sterilising or functional cure intervention against other interventions that may achieve similar effects. For example, a sterilising HIV cure might encounter difficulties in implementation not experienced by programs to increase barrier contraception use, or other strategies to break transmission of HIV. Moreover, allocating resources to surmount one set of challenges may come at the expense of other potential implementation strategies. Evaluating the value of scientific research as an actualist involves assessing its implementation as a necessary component of the instrumental value of research.

\section{Objections}

A possibilist might reply with three objections:

1. Actualism is fatalistic. Scientific research that finds no application now might be just a generation, a political administration or a wealthy benefactor away from making a better world.

2. Actualism is overly demanding in terms of the epistemic burden required to ascertain whether or not research will actually lead to a working cure for HIV. Whether or not actualism holds, it is impossible to put into practice.

3. One could be an actualist for the purpose of honing interventions and their implementation but a possibilist for the purposes of prioritising research.

\section{The actualist's reply}

These three objections, we believe, can be successfully resisted. To the first, an actualist will indeed rank their options in a way that accounts for changes in politics, but we do not take this to be fatalistic. In the case of a HIV cure, a candidate cure is arguably more desirable if its deployment is not contingent on particular kinds of funding or aid programmes that may vanish with a change in government. Actualism can account for current institutional arrangements being subject to change, while still requiring that proposed research be sensitive to present and expected future institutional arrangements.

The second concern is about actualism's demandingness characteristic, but it could also be about the incentives that actualism places on researchers. Consider, for example, the AZT (zidovudine) 076 breakthrough that led to the WHO conference to find an affordable and accessible AZT regimen for HIV-positive pregnant women in low-income countries. ${ }^{29}$ Given how difficult and costly drug/device development is, it might seem like an extra hurdle to attempt to secure implementation commitments before the development has shown promise. Accepting actualism does not entail that scientists themselves make such determinations. Individual scientists are rarely the best qualified to make complex, institutional evaluations of their own work. ${ }^{16}{ }^{30}$ Governments, academic institutions and funding bodies, however, may have the epistemic and logistical capacities to make these assessments and are moreover in a position to inform the direction of research through funding mechanisms. A commitment to actualism requires only that scientific research be evaluated in terms of its capacity to actually bring about a valuable outcome and not who the evaluator ought to be.

Moreover, judging what lines of inquiry are most likely to succeed is challenging even if one is a possibilist. Uncertainty about, say, the technical possibility of a cure is the same, independent of the stance one takes about actualism. Actualists do not differ from possibilists on questions that turn on the likelihood of a line of inquiry paying dividends in the form of promoting health (or some other good). There is evidence that 'blue skies' research, for example-research that is not pursued with an explicit pragmatic goal in mind, but rather out of curiosity about some feature of the natural world — can lead to considerable benefits ${ }^{31}$; an actualist can acknowledge the value of blue skies research while maintaining the argument that when discussing priorities of goal-driven clinical research, we ought to account for our motivations to carry out our actions. If actualist considerations are burdensome, it is only a matter of degree, not of kind. And, as we claim, there is no in-principle reason why deliberation about feasibility ought to be something pursued by lone researchers.

The third objection is curious: on the one hand, it appears to reveal some kind of 'moral split personality', whereby the relationship between an agent's reasons for action and their motivation to carry out that action changes by turns at different stages of a particular activity. On the other hand, it mirrors a stereotype of scientist's indifference to the practical outcomes of their work, exemplified by Robert Oppenheimer: 'When you see something that is technically sweet, you go ahead and do it and argue about what to do about it only after you've had your technical success'. Our response is simply that in the case we provide, if Do-Good decides to become an actualist after deciding to fund the research, they will consistently end up with the worst outcome, as judged by both the actualist and the possibilist. That is, Do-Good qua possibilist funder of science will fund the cure research, but qua actualist will then choose a more plausible line of implementation even if the research exists, because the problems of implementation are external to the mere existence of the cure research. In practice-given multiple research options-we might not always see the worst outcomes were we to try and be possibilists and actualists, but we are less likely to see the best, or good outcomes, at least when judged from the perspective of the social value of research.

In light of our responses to objections two and three, however, one could envisage a division of labour where scientists are possibilists, but funders are actualists. Here, the tension is less apparent, because each role-holder maintains a single identity. Given that the scope of our inquiry relates to whether we should fund and pursue research, we maintain that funders should be actualists. As a preliminary response to the question of scientists, it seems likely that if our account of actualism holds, then scientists ought to be actualists as well. Note, however, that actualism is concerned with what an agent ought to do, given their own motivations-there is a separate question, which we discuss in following sections, about what an agent ought to do in response to the motivations of others. Insofar, however, as scientists are in general neither capable nor responsible for, say, eradicating a disease single-handedly, then the obligations that follow from their actualism qua a cure for HIV/AIDS are more limited. 


\section{WHAT DO WE NEED FOR A VALUABLE HIV CURE?}

If we accept actualism about the value of scientific research, what kinds of factors will determine the value of a candidate cure? For an HIV cure to be valuable, it needs to be the following:

i. Effective: scientific and technical challenges will need to be overcome in order to attain a cure that is effective at eliminating the virus or eliciting long-term viral remission.

ii. Safe to use: not simply in the context of developed medical systems, but over a wide range of healthcare modalities;

iii. Simple: able to be effectively used in a range of community settings, with a focus on locales who bear significant burdens of mortality and morbidity from HIV/AIDS;

iv. Scalable: able to be manufactured, distributed and stored on a global scale.

\section{Scientific/technical challenges in developing an effective HIV cure}

HIV eradication from the human host is challenging because the virus has the ability to hide in cells that lie dormant while evading host immune mechanisms. The biggest challenge in curing HIV is finding a drug that forces the virus out of all latent reservoirs that have been established in the HIV-infected person. ${ }^{32}$ Latency reversing interventions seek to overcome this barrier using drugs that can awaken the virus from dormant cells to make them accessible to drugs that can kill the awakened virus.

An additional challenge in HIV cure research is the absence of sensitive technologies that can prove that the virus has been completely purged and an individual no longer has $\mathrm{HIV}^{33}$ Interventions that aim to completely eradicate the virus will require a tool that can prove the absence of HIV in a previously infected person.

Based on feasibility and likelihood of eliminating the virus, with no consideration for implementation, the candidate interventions can be ranked and prioritised from the possibilist perspective as follows:

1. Cell-based therapy: In theory, it would be a one-time treatment to 'cure' an otherwise chronic disease.

2. Latency reversing agents: This combination approach promises a long-term ART-free remission.

3. Early intensive ART treatment for neonates: This intervention could bring about long-term ART-free remission in infants.

4. Immune-based interventions: Therapeutic vaccines or antibodies may not eliminate the virus but they could lead to long-term ART-free remission.

Implementation challenges for future HIV cure interventions Several examples exist of health technologies that worked effectively in developed countries, but which failed to perform in low-resource settings. Strategies like prophylactic ART and replacement feeding have worked well in programmes to prevent mother-to-child HIV transmission (PMTCT) in developed countries. However, in some low-income countries with limited access to healthcare and clean water, implementation has failed due to these strategies being untested or unsuitable. ${ }^{34}$

In the remainder of this paper, we examine the challenges in implementing the HIV cure research that are surmountable with effort and the challenges that in actuality are unlikely to be surmountable. We list these challenges in order of resolvability and, finally, we 're-prioritise' cure interventions accordingly.

\section{Healthcare worker shortages}

Many low-income countries have inadequate trained healthcare workers and this could be a major barrier for implementing HIV cure interventions. Rather than train new healthcare workers in resource-limited settings to perform medically complex cell-based therapy procedures, it would be more costeffective and sustainable to use workers who are already involved in treating other diseases. ${ }^{34}$ Also, auxiliary health workers could be properly integrated into health systems to fill in the gaps created by healthcare worker shortages and strengthen health systems in low-income countries. Preliminary analysis by the Elizabeth Glaser Pediatric AIDS Foundation of the implementation of WHO policy guidelines for PMTCT in some African countries shows that it is feasible to train additional healthcare workers to scale up HIV therapy. ${ }^{35}$

\section{Public reluctance to accept new health technologies and adherence challenges}

We foresee patients who are doing well on ART or who have their HIV under control being hesitant to try out potentially risky yet relatively valuable HIV cure interventions like cellbased therapy or latency reversing treatment. Put another way, patients may not value a sterilising or functional cure if the management of HIV through ART is seen as sufficient or preferable to novel interventions. Results from a qualitative study on barriers to ART initiation in Swaziland showed that community outreach and engagement helped in increasing ART acceptance. ${ }^{35}$ It is realistic that initial public reluctance towards a cure can be overcome with some effort. To resolve adherence challenges, researchers should prioritise developing one-time interventions requiring single hospital visits or short course regimens that eliminate the need for follow-up visits.

\section{Financing cost and delivery of interventions}

Worldwide, drug prices usually determine their accessibility. At present, the cost of cell-based therapy is very high-autologous cell transplant is estimated at US\$75 000-\$150000 and allogeneic cell transplant is estimated at US\$150 000-\$300,000. ${ }^{36} 37$ These estimated costs remain lower than the current cost of lifelong ART in developed countries, which is estimated at US \$420 000-\$755000 per individual in the USA. ${ }^{38}$

While the price of cure interventions will likely become lower with time, some elements of cost are insurmountable. In lowincome countries, sophisticated and technology-intensive HIV cure interventions like cell-based therapy will be challenging to deliver in rural regions without reliable power supply. The apheresis procedure, which is used for collecting cells (T cells or stem cells) in cell-based therapy, is medically and technically demanding and is not currently available worldwide. As of 2014, only one country (out of 16) in West Africa had the capacity to perform apheresis procedures. ${ }^{39}$ Overcoming these technical challenges would require strengthening health systems in lowincome countries and making resources available to transport people from rural regions to urban centres that are equipped to deliver these complex interventions. Constrained public budgets make it difficult for governments in low-income countries to purchase innovative health technologies for use in healthcare centres. $^{40}$ As such, political commitment and donor efforts would need radical expansion to support access to a complex or sophisticated candidate cure. We are not confident that such an expansion is likely to occur; bottlenecks to point-of-care delivery will remain. As actualists, these bottlenecks support the argument for prioritising less complex cure interventions. 


\section{High-risk intervention}

Cell-based therapy that involves stem cell transplantation is highly risky and requires continuous medical attention and immunosuppressant use. Some latency reversing agents currently being considered for HIV cure are mutagenic and may potentially cause cancer in the long term. ${ }^{6}$ Unless transformed to become low-risk with fewer inpatient procedures, it will be challenging to convince patients who are doing very well on ART to undergo these potentially risky interventions.

\section{'RE-PRIORITISING' CURE INTERVENTIONS}

Given that not all upcoming HIV cure research will live up to its promise, we submit a prima facie ranking of the four candidate HIV cure interventions from most to least attractive, given their feasibility and likelihood of success, implementation and use to reduce the burden of HIV/AIDS:

1. Latency reversing treatment: It is the most attractive cure option because it seeks to target and eliminate hidden HIV virus in dormant cells, which will resolve current scientific challenges. In terms of scalability, it has the potential for delivering a limited dose combination that will be safe, simple and easily scalable globally.

2. Immune-based interventions: Therapeutic vaccines or antibodies may not eliminate all traces of the virus ${ }^{41}$ but they have a strong likelihood of being used in combination doses that will ensure long-term ART-free remission. This will also likely be safe, simple and easily scalable globally.

3. Early intensive ART treatment for neonates: This intervention could bring about long-term ART-free remission by preventing the virus from hiding in permanent latent reservoirs. In terms of global impact, it would be a relatively low-cost intervention available to infants and could greatly reduce the number of new HIV cases acquired through birth.

4. Cell-based therapy: It is a high-cost and high-risk intervention, which is challenging to perform in resource-limited settings. The absence of advanced medical technology and skilled health professionals in low-income countries limits the scalability and global implementation of this intervention, making it the least attractive option.

The fourth option in particular is in principle possible, but implementation challenges make us question its usefulness in making a strong impact on the global HIV burden. We suggest therefore that other more attainable treatment interventions should be prioritised over cell-based therapy and research funders should take that into account.

An important limitation to our account is the degree to which the above conditions are relevantly components of the actor's decisions. In the example we set out at the beginning, the catch was that Do-Good would not in fact pursue a cure-not, necessarily, that Do-Good would pursue the cure, but that some other actor with a crucial role in the cure process would not, in fact, do their job. In a complex international environment, for example, joint actions or issues that bear on the sovereignty of other nations may not relevantly bear on an actor qua single government's motivations to act. Our ranking primarily depends on concerns that are within the domain of a single actor's action as they consider funding research and rolling out a cure, such as safety, cost and scalability. This ranking will be subject to change, however, depending on the identity of the actor.

A further conceptual issue concerns the obligations of actors, given their beliefs about the actions and motivations of other parties with whom they are engaged in a joint action. There are accounts of political feasibility that make use of an extended conception of Jackson's and Pargetter's framework ${ }^{42}$ when considering our obligations over conjunctions of actions when those actions are dependent on others, but a full analysis of this literature is beyond the scope of our work. According to our analysis, were the above limitations to a cure issues that depended solely on the actions of others, then the possibilist and actualist rankings would, all other things being equal, be the same.

However, we think that many of these factors are within the scope of an actor such as a nation-state to consider. Take, for example, cell-based therapies, which are among the most expensive cure options. We could recast part of Do-Good's narrative in this way:

However, suppose that Do-Good knows that the drug will not be used; not because of physical limitations or logistical incapacity, but because Do-Good would have to offer the drug for free to patients suffering from this disease, and Do-Good would be unwilling to make this offer. (This has been known to happen.) Thus, although the best thing that can happen is for Do-Good to develop the drug and cure millions, and exactly this could happen, what would happen were research pursued is that the drug would not be used.

Many of the limitations on candidate cures depend in part on the actions of others, but there are central aspects of these factors that can or do depend on actors funding the research, such as national governments. Here, we have been permissive in what we count as relevant in the realm of being an actor-centred action; we leave open the possibility that there may be a more compelling account of joint actions that relegates these factors to another framework outside the purview of our analysis here.

\section{CONCLUSION}

Actualism about HIV cure research argues that the value of research should be prescribed by the likelihood of success and the prospects for implementing the research, given what we know about global health.

Our analysis has two broad implications. The first is that we ought to consider a range of non-sterilising or functional cure options and compare the prospects for reducing the burden of the HIV epidemic through these interventions against candidate cures. Second, the framework in which science simpliciter is evaluated, under actualism, is one in which science is not considered exceptional as a vehicle for human health and prosperity. Contemporary bioethical discussions about health technologies tend to privilege discussions that regard health technologies as essential to human progress and a moral imperative existing to pursue any and all research that could lead to an improvement in human well-being. ${ }^{43-45}$ What matters to an actualist, however, is promoting human health, not that it is science doing the promotion. Given how expensive modern biomedicine is, even to produce modest returns in human health, any investment in health technologies should be ranked against other potential investments according to our beliefs about political and social factors that lead to implementation.

Governments, academic institutions and funding bodies can make informed decisions about priority setting for HIV cure research using epistemic and logistical assessments. This, on our analysis, renders them responsible for setting priorities in research based on the feasibility of implementing the medical interventions they seek to develop. This has broader implications for the way that research is reviewed and, in particular, the makeup of expert committees that assess proposed research. The practice of research review should be broadened to include individuals with the expertise to inform decisions of the kind we described here. 
A cure for HIV is an attractive goal. When selecting candidate cures, however, we ought to be mindful of the kinds of barriers to implementation that each cure faces, especially in the developing world. A cure that few can afford, use or otherwise actually derive benefit from is deficient qua cure.

Twitter Follow Nicholas G. Evans at @neva9257

Acknowledgements The authors would like to thank Steve Joffe, Christine Grady, Nir Eyal and Danielle Bromwich for their comments on drafts of this paper.

Contributors Regina Brown and Nicholas Evans are the sole authors of this paper.

Funding This work is supported by the US National Institute of Allergy and Infectious Diseases (R56 Al114617 and R01 Al114617).

Competing interests None declared.

Provenance and peer review Not commissioned; externally peer reviewed.

Acknowledgement, post peer-review The authors thank Nir Eyal, Christine Grady, Steven Joffe, Danielle Bromwich, participants at the Harvard Chan School HIV Cure Ethics Symposium, and members of the University of Massachusetts Lowell Department of Philosophy for their comments on early versions of this paper.

Open Access This is an Open Access article distributed in accordance with the Creative Commons Attribution Non Commercial (CC BY-NC 4.0) license, which permits others to distribute, remix, adapt, build upon this work non-commercially, and license their derivative works on different terms, provided the original work is properly cited and the use is non-commercial. See: http://creativecommons.org/ licenses/by-nc/4.0/

\section{REFERENCES}

1 Kumar R. Contractualist reasoning, HIV cure clinical trials, and the moral (ir) relevance of the Risk/Benefit Ratio. JME 2016.

2 Emanuel EJ, Wendler D, Killen J, et al. What makes clinical research in developing countries ethical? The benchmarks of ethical research. J Infect Dis 2004;189:930-7

3 Rid A, Wendler D. A framework for risk-benefit evaluations in biomedical research. Kennedy Inst Ethics I 2011;21:141-79.

4 Howitt P, Darzi A, Yang GZ, et al. Technologies for global health. Lancet 2012;380:507-35.

5 Grossman CM. The first use of penicillin in the United States. Ann Intern Med 2009; 150:737

6 Kuritzkes DR. Why Cure, Why Now? JME 2016;doi:10.1136/ medethics-2015103113

7 Hütter G, Nowak D, Mossner M, et al. Long-term control of HIV by CCR5 Delta32/ Delta32 stem-cell transplantation. N Engl J Med 2009;360:692-8.

8 Allers $K$, Hütter $G$, Hofmann J, et al. Evidence for the cure of HIV infection by CCR5 $32 / \Delta 32$ stem cell transplantation. Blood 2011:117:2791-9.

9 Stan R, Zaia JA. Practical considerations in gene therapy for HIV cure. Curr HIV/ AIDS Rep 2014;11:11-19.

10 Deeks SG. HIV: Shock and kill. Nature 2012;487:439-40.

11 Archin NM, Liberty AL, Kashuba AD, et al. Administration of vorinostat disrupts HIV-1 latency in patients on antiretroviral therapy. Nature 2012;487:482-5.

12 Halper-Stromberg A, Lu CL, Klein F, et al. Broadly neutralizing antibodies and viral inducers decrease rebound from HIV-1 latent reservoirs in humanized mice. Cell 2014;158:989-99.

13 Anderson JL, Fromentin R, Corbelli GM, et al. Progress towards an HIV cure: update from the 2014 International AIDS Society Symposium. AIDS Res Hum Retroviruses 2015:31:36-44.

14 Smith PL, Tanner H, Dalgleish A. Developments in HIV-1 immunotherapy and therapeutic vaccination. F1000Prime Rep 2014;6:43, 43. eCollection 2014.

15 Persaud D, Gay H, Ziemniak C, et al. Absence of detectable HIV-1 viremia after treatment cessation in an infant. N Engl I Med 2013;369:1828-35.

16 Evans NG. Great expectations-ethics, avian flu and the value of progress. J Med Ethics 2013;39:209-13.
17 Evans NG. Valuing knowledge: a reply to the epistemological perspective on the value of gain-of-function experiments. MBio 2014;5:e01993-14.

18 MDG 6: 15 years, 15 lessons of hope from the AIDS response. http://www.unaids. org/sites/default/files/media_asset/20150714_FS_MDG6_Report_en.pdf (accessed 10 Dec 2015)

19 Estimates of Funding for Various Research, Condition, and Disease Categories (RCDC). http://report.nih.gov/categorical_spending.aspx (accessed 10 Dec 2015).

20 Global investment in HIV cure research and development 2014. http://www. iasociety.org/Web/WebContent/File/Towards_and_HIV_Cure_Tracking_Paper_2014. pdf (accessed 10 Dec 2015).

21 Baeten JM, Donnell D, Ndase P, et al. Antiretroviral prophylaxis for HIV prevention in heterosexual men and women. N Engl J Med 2012;367:399-410.

22 Choopanya K, Martin M, Suntharasamai P, et al. Antiretroviral prophylaxis for HIV infection in injecting drug users in Bangkok, Thailand (the Bangkok Tenofovir Study): a randomised, double-blind, placebo-controlled phase 3 trial. Lancet 2013;381:2083-90.

23 Grant RM, Lama JR, Anderson PL, et al. Preexposure chemoprophylaxis for HIV prevention in men who have sex with men. N Engl J Med 2010;363: 2587-99.

24 Fauci AS, Marston HD. Ending the HIV-AIDS pandemic-follow the science. N Engl J Med 2015;373:2197-9.

25 Jackson F, Pargetter R. Oughts, options, and actualism. Philos Rev 1986;95:233.

26 Evans NG. Dual-use decision making: relational and positional issues. Monash Bioeth Rev 2014:32:268-83.

27 Lawford-Smith H. Non-ideal accessibility. Ethic Theor Moral Pract 2013;16:653.

28 Schwenkenbecher A. Joint moral duties. Midwest Stud Philos 2014;38:58.

29 Mother-to-child transmission of HIV. http://www.unaids.org/sites/default/files/media_ asset/ic531-mtct-tu_en _0.pdf (accessed 28 Jan 2016).

30 Selgelid MJ. A tale of two studies; ethics, bioterrorism, and the censorship of science. Hastings Cent Rep 2007;37:35-43.

31 Linden B. Basic Blue Skies Research in the UK: Are we losing out?. J Biomed Discov Collab 2008:3:3, 5333-3-3.

32 Fauci AS, Folkers GK. Investing to meet the scientific challenges of HIV/AIDS. Health Aff (Millwood) 2009;28:1629-41.

33 A Cure for HIV. http://hivinsite.ucsf.edu/lnSite?page=md-expert-deeks-pillai (accessed 28 January 2016).

34 Madon T, Hofman KJ, Kupfer L, et al. Public health. Implementation science. Science 2007;318:1728-9.

35 Kieffer MP, Mattingly M, Giphart A, et al. Lessons learned from early implementation of option B+: the Elizabeth Glaser Pediatric AIDS Foundation experience in 11 African countries. J Acquir Immune Defic Syndr 2014;67(Suppl 4): S188-94.

36 NBMTL. Question 8: How much does a transplant cost? And how will I pay for all of this? In: Anonymous. Bone Marrow/Stem Cell Transplant, Frequently asked question. Michigan: National Bone Marrow Transplant Link, 2012:9.

37 Sax PE, Sypek A, Berkowitz BK, et al. HIV cure strategies: how good must they be to improve on current antiretroviral therapy? PLOS ONE 2014; 9:e113031.

38 Schackman BR, Gebo KA, Walensky RP, et al. The lifetime cost of current human immunodeficiency virus care in the United States. Med Care 2006:44:990-7.

39 Eichbaum Q, Smid WM, Crookes R, et al. Apheresis in developing countries around the World. J Clin Apher 2015;30:238-46.

40 Frost LJ, Reich MR. Access: how do good health technologies get to poor people in poor countries? Cambridge, MA: Harvard University Press, 2009.

41 Fauci AS, Marston HD, Folkers GK. An HIV cure: feasibility, discovery, and implementation. JAMA 2014:312:335-6.

42 Lawford-Smith H. The Feasibility OF Collectives' Actions. Australas J Philos 2012:90:453.

43 Savulescu J, Pugh J, Douglas T, et al. The moral imperative to continue gene editing research on human embryos. Protein Cell 2015;6:476-9.

44 Green RC, Farahany NA. Regulation: The FDA is overcautious on consumer genomics. Nature 2014:505:286-7.

45 Angrist M. The audacity of interpretation: Protecting patients or piling on? Appl Transl Genom 2014;3:68-9. 